\title{
Identification of a Maize Kernel Pathogenesis-Related Protein and Evidence for Its Involvement in Resistance to Aspergillus flavus Infection and Aflatoxin Production
}

\author{
Z.-Y. Chen, R. L. Brown, K. Rajasekaran, K. E. Damann, and T. E. Cleveland
}

First and fourth authors: Department of Plant Pathology and Crop Physiology, Louisiana State University Agricultural Center, Baton Rouge, LA 70803; and second, third, and fifth authors: Southern Regional Research Center, United States Department of Agriculture-Agricultural

Research Service, New Orleans, LA 70179.

Accepted for publication 11 August 2005.

\begin{abstract}
Chen, Z.-Y., Brown, R. L., Rajasekaran, K., Damann, K. E., and Cleveland, T. E. 2006. Identification of a maize kernel pathogenesisrelated protein and evidence for its involvement in resistance to Aspergillus flavus infection and aflatoxin production. Phytopathology 96:87-95.

Aflatoxins are carcinogens produced by Aspergillus flavus and A. parasiticus during infection of susceptible crops such as maize. Several aflatoxin-resistant maize genotypes have been identified and kernel proteins have been suggested to play an important role in resistance. In the present study, one protein (\#717), which was expressed fivefold higher in three resistant lines compared with three susceptible ones, was identified using proteomics. This protein was sequenced and identified as a pathogenesis-related protein (PR-10) based on its sequence

homology. To assess the involvement of this PR-10 protein (ZmPR-10) in host resistance of maize against fungal infection and aflatoxin production, the corresponding cDNA ( $p r-10)$ was cloned. It encodes a protein of 160 amino acids with a predicted molecular mass of $16.9 \mathrm{kDa}$ and an isoelectric point of 5.38. The expression of $p r$ - 10 during kernel development increased fivefold between 7 and 22 days after pollination, and was induced upon A. flavus infection in the resistant but not in the susceptible genotype. The ZmPR-10 overexpressed in Escherichia coli exhibited a ribonucleolytic and antifungal activities. Leaf extracts of transgenic tobacco plants expressing maize $p r-10$ also demonstrated RNase activity and inhibited the growth of $A$. flavus. This evidence suggests that ZmPR10 plays a role in kernel resistance by inhibiting fungal growth of A. flavus.
\end{abstract}

Infection of maize (Zea mays L.) by Aspergillus flavus and the subsequent accumulation of the toxic and highly carcinogenic secondary metabolites, aflatoxins, is a serious agricultural problem, especially in maize grown under dry conditions $(19,37)$. Aflatoxin contamination significantly reduces the value of grain both as an animal feed and as an export commodity (35). It also poses health threats to humans (37) and domestic animals (35).

During the past two decades, maize genotypes with natural preharvest resistance to aflatoxin production have been identified through field screening $(6,39,46)$. The poor agronomic quality of these lines, however, renders them of little direct commercial value (4). The lack of identified markers in these genotypes also has slowed the incorporation of resistance into lines with commercially acceptable genetic backgrounds.

The expression of maize kernel proteins has been implicated in kernel resistance to A. flavus infection or aflatoxin production $(17,18,21,25)$. A constitutively expressed $14-\mathrm{kDa}$ trypsin inhibitor (TI) protein was associated with resistance through comparisons of mature kernel proteins between resistant and susceptible genotypes using one-dimensional polyacrylamide gels. This protein is expressed at high levels in the endosperm of resistant lines, but was at low levels or absent in susceptible lines (13). TI demonstrated strong bioactivity in vitro against A. flavus and other fungal pathogens (12), possibly through inhibition of A. flavus $\alpha$-amylase production and activity (14). Inhibiting $\alpha$-amylase

Corresponding author: R. L. Brown; E-mail address: rbrown@ srrc.ars.usda.gov

DOI: 10.1094/PHYTO-96-0087

This article is in the public domain and not copyrightable. It may be freely reprinted with customary crediting of the source. The American Phytopathological Society, 2006. could hinder fungal ability to utilize endosperm sugars, the known carbon source for both fungal growth and aflatoxin biosynthesis (47).

Several additional proteins that are either unique or expressed at higher levels in resistant lines were identified when constitutive embryo proteins of resistant maize genotypes were compared with susceptible ones using a proteomics approach (10). These proteins have been categorized as storage proteins, stress-related proteins, or antifungal proteins based on their corresponding peptide sequence homology (10). Some have been reported to play a role in stress tolerance in other plants $(28,36,41,42,48)$. Further characterization of one such stress-related protein, glyoxalase I, suggested that it may play an important role in kernel resistance by controlling the cytotoxic methylglyoxal level inside kernels. Because methylglyoxal is an aflatoxin inducer, the higher glyoxalase I activity could contribute to the lower levels of aflatoxins found in infected resistant maize kernels (11).

In the present study, a comparison of constitutive kernel endosperm proteins between three resistant and three susceptible genotypes using proteomics has identified a protein whose level of expression was fivefold higher in resistant lines compared with susceptible ones. This protein was sequenced and identified as a pathogenesis-related protein (PR-10). PR-10 proteins are a family of intracellular, acidic proteins, with a molecular mass of 16 to $19 \mathrm{kDa}$ that lack a signal peptide and are resistant to proteases (43). However, the biological function or functions of this class of proteins remains unknown, although a white lupin PR-10-like protein has been shown to possess ribonuclease activity (2).

The objective of the current study was to investigate the potential of this maize protein, $\mathrm{ZmPR}-10$, to play a role in maize host resistance to A. flavus infection and aflatoxin contamination. Here, we cloned both cDNA and the genomic DNA of pr-10 
based on peptide sequences obtained through electrospray ionization tandem mass spectrometry (ESI-MS/MS), examined its expression during kernel development with or without fungal infection using real-time reverse-transcriptase polymerase chain reaction (RT-PCR), and demonstrated RNase activity of the protein in vitro using the ZmPR-10 protein overexpressed in and purified from Escherichia coli. Further, we transformed tobacco plants with maize $p r-10$ and demonstrated increased antifungal activity in the leaf extracts of transgenic plants against A. flavus and Verticillium dahliae compared with the control plants. A preliminary report has been published (9).

\section{MATERIALS AND METHODS}

Chemicals and materials. Chemicals for two-dimensional (2D) protein gels and kernels of resistant (Mp420, Mp313E, and GT-MAS:gk) and susceptible (B73, Mo17, and Va35) maize genotypes were obtained from the same sources as in a previous study (10). Resistance or susceptibility of these genotypes to aflatoxin accumulation was determined by breeders in field trials repeated over different environments and times using artificial and natural infection $(6,39,46)$. Aflatoxin standards were purchased from Sigma-Aldrich (St. Louis) and prepared according to the manufacturer's instructions.

Protein extraction and gel electrophoresis. Kernels (20 g) from each genotype were dissected into embryo and endosperm as described (10). Endosperm tissues were frozen in liquid nitrogen and ground to powder in an analytical mill (Tekmar A-10; Janke and Kunkel GmbH \& Co., Staufen, Germany). Powdered endosperm was extracted with an extraction buffer $(0.25 \mathrm{M} \mathrm{NaCl}$, $50 \mathrm{mM}$ Tris- $\mathrm{HCl}$ [pH 8.0], $14 \mathrm{mM} \beta$-mercaptoethanol) $(2 \mathrm{ml} / \mathrm{g})$ for $2 \mathrm{~h}$ at $4^{\circ} \mathrm{C}$, and then supernatant was recovered and desalted as described (10). The extracted protein was resolubilized in lysis buffer $(9.5 \mathrm{M}$ urea, 2\% CHAPS, $1 \%$ dithiothreitol, $0.8 \%$ [wt/vol] immobilized $\mathrm{pH}$ gradient buffer, $\mathrm{pH} 3$ to 10 , and $0.04 \%$ Pefabloc proteinase inhibitor) at a final concentration of $2 \mu \mathrm{g} / \mu \mathrm{l}$ for analytical gels and $20 \mu \mathrm{g} / \mu \mathrm{l}$ for preparative gels.

Endosperm protein (analytical, $50 \mu \mathrm{g}$; and preparative, $700 \mu \mathrm{g}$ ) was applied to rehydrated 17-cm Immobiline DryStrip gels $(\mathrm{pH} 3$ to 10). First- and 2-D gel electrophoresis was performed as described (10). Protein spots in analytical gels were stained automatically with a Silver Stain Kit (Genomic Solutions, Chelmsford, MA) using an Investigator Gel Processor (Genomic Solutions). Preparative gels were stained with Coomassie Brilliant Blue R 250. All stained gels were scanned using a UMAX Power-

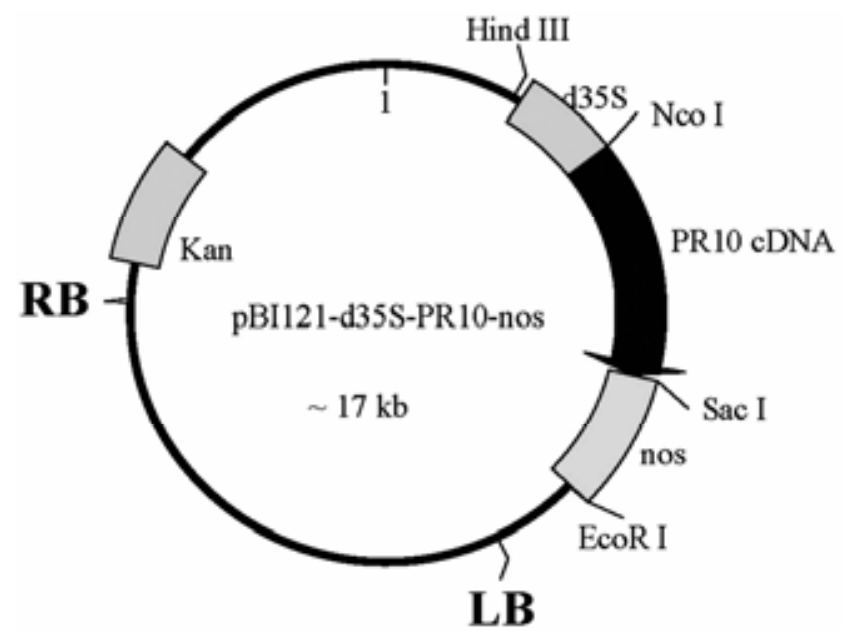

Fig. 1. Map of pBI121-d35S-PR-10-nos construct used in the transgenic expression of maize $p r-10$ gene in tobacco. $\mathrm{LB}$ and $\mathrm{RB}$, left and right borders, respectively, of T-DNA; d35S, double 35S promoter from Cauliflower mosaic virus; nos, terminator from nopaline synthase gene of Agrobacterium tumefaciens.
Look II scanner (UMAX data systems, Taiwan), and analyzed using Progenesis Discovery 2003 software package (Nonlinear Dynamic, Durham, NC). Only the reproducible spots were used for comparison $(>90 \%$ of all protein spots detected on $2-\mathrm{D}$ gels for a given genotype are reproducible). The normalized spot intensity, which was adjusted for loading and staining variations between gels, was used for protein level comparison.

Peptide sequencing and database sequence homology analysis. Protein \#717 was recovered from five preparative 2-D gels and sequenced as previously described using PE SCIEX API 3000 (Applied Biosystems, Foster City, CA) ESI-MS/MS equipped with a Protana nanospray source (Odense, Denmark) (10). Peptide sequence homology searches were performed using BLAST (1) against known proteins or translated open reading frames of expressed sequence tags (ESTs) in databases at the National Center for Biotechnology Information (NCBI) and SWISS-Prot.

Cloning of full-length pr-10 cDNA. Two degenerate primers were made, 5'-CCIGT(G/C/T)GA(G/A)GGIGA(C/T)GG-3' (PR10-F1) and 5'-GG(G/A)TTIGC(C/G/A)ACIAG(G/A)TAIGC(C/T)TC-3' (PR-10-R1), based on peptide sequences PVEGDG and EAYLVANP, respectively. The first round of PCR was performed in $50 \mu \mathrm{l}$ using M13(-20) and PR-10-R1 primer pair and $1 \mu \mathrm{l}$ of undiluted maize endosperm cDNA library made from Ohio 43 kernels 10 to 14 days after pollination (titer $1.1 \times 10^{7}$ plaque forming units per ml) (provided by R. J. Schmidt, Division of Biology, University of California, San Diego). The second-round PCR was performed using the PR-10-F1 and PR-10-R1 pair and $1 \mu \mathrm{l}$ of 1:20 diluted first-round PCR product as the template. The amplified 0.4-kb PCR product was cloned into the pCR2.1-TOPO vector (Invitrogen, Carlsbad, CA). DNA sequences of five independent clones were identical and aligned to the rice $p r-10$ gene. The remaining sequences of $p r-10$ cDNA were cloned using $5^{\prime}$ and $3^{\prime}$ rapid amplification of cDNA ends (RACE) as previously described (11) with primers from the cDNA library vector and gene-specific primers (PR-10-F2: 5'-ACTTACAAGCTGCTGCCGGG and PR-10-F3: 5'-AGGTGAAGGACGAGATCGCC for cloning the $3^{\prime}$ end; PR-10-R2: TCCAGGAACTCGAGCCTCTC and PR-10-R3: GAACGGCATGACTGAGGTGA for cloning the $5^{\prime}$ end) derived from the sequenced $0.4-\mathrm{kb}$ PCR product.

Construction of vectors for bacterial and plant expression. The coding region of $p r-10$ cDNA was amplified using two primers (PR-10-Nco I: TGAAGTAGccATGGCCTC, and PR-10-Sac I: AATGgAGCTCATCCCAGT). The nucleotide changes (lowercase) to incorporate an $\mathrm{NcoI}$ site at the $5^{\prime}$ end (by changing TA to $\mathrm{CC}$ ) and a SacI site at the $3^{\prime}$ end (by changing T to C) did not alter any amino acid sequence of the ZmPR-10. The PCR product was digested with $\mathrm{NcoI}$ and $\mathrm{SacI}$, gel purified, and then cloned into corresponding sites of the pET28c vector (Novagen, Madison, WI) and the pBS-d35S-D4E vector (provided by J. Cary, United States Department of Agriculture (USDA)-Agricultural Research Service, Southern Regional Research Center) to generate pET28c-PR-10 and pBS-d35S-PR-10, respectively. The latter then was digested with HindIII and SacI to excise the 1.4-kb d35S-PR-10 insert, which then was cloned into the HindIII and SacI double-digested and dephosphorylated pBI121 vector. The resulting construct was named pBI121-d35S-PR-10-nos (Fig. 1). Correct constructs were verified during each step of cloning through DNA sequencing.

Genomic DNA and total RNA isolation. Genomic DNA of resistant maize genotype Mp420 or transgenic tobacco was isolated from young leaf tissue according to the instructions of the Redextract-N-Amp Plant PCR kit (Sigma-Aldrich). The pr-10 genomic clone was obtained from Mp420 genomic DNA using primers corresponding to the $5^{\prime}$ and $3^{\prime}$ ends of $p r-10 \mathrm{cDNA}$. Total RNA was isolated from immature maize kernels of different developmental stages or from tobacco leaf tissues using the RNeasy Plant mini kit (Qiagen, Valencia, CA) according to the manufac- 
turer's instructions. The optional DNase treatment was included to remove trace DNA contamination before proceeding to realtime RT-PCR.

Expression of the $p r$-10 gene during different stages of kernel development with or without $A$. flavus inoculation. The expression of the pr-10 gene during kernel development was examined in one resistant (GT-MAS:gk) and one susceptible (Mo17) genotype. One-third of the plants from each genotype was inoculated in the field with an A. flavus conidial suspension at $5 \times 10^{6} / \mathrm{ml}$ using a syringe 7 days after pollination (DAP). Another one-third was wounded with a syringe needle without inoculum to serve as a wounded-only control. The remaining onethird was used as a noninfected (nonwounded) control. Kernels were collected at $0,3,8$, and 15 days after inoculation $(7,10,15$, and 22 DAP, the time period with active gene expression, protein biosynthesis, and linear grain fill inside kernels). For wound-only and inoculated ears, only the healthy-looking kernels surrounding the wounded or infected kernels were harvested.

Total RNA was reverse transcribed into cDNA using TaqMan Reverse Transcription Reagents (Applied Biosystems, Foster City, $\mathrm{CA}$ ) according to the manufacturer's instructions. The level of $\mathrm{pr}$ 10 expression then was quantified using ABI 5700 Thermal Cycler with SYBR Green dye chemistry (Applied Biosystems). Primers used in real-time PCR (PR-10-F, 5'-CACCTCAGTCATGCCGTTCA; and PR-10-R, 5'-CCCTCGATGAGCGTGTTCTT) were designed using Primer Express 2.0 (Applied Biosystems). The amplicon size was $90 \mathrm{bp}$. PR-10-F was designed to span the intron of its genomic DNA sequence so that it only amplifies cDNA sequence. To check the specificity of annealing of the oligonucleotides, dissociation kinetics was performed by the machine at the end of the experiment. In addition, each amplified product was sequenced. The expressions of $18 \mathrm{~S}$ and actin (forward: CTCAGGCCAAGAGAGGCATC, and reverse: TGCCATGCTCAATCGGGTA) in maize kernels were used as internal controls to normalize the expression of $p r-10$ gene (27). This experiment was repeated at least twice for cDNA prepared for two batches of isolated RNA samples. Using standardized conditions, deviations of threshold values were less than 1.0 cycle for independent cDNA preparations and less than 0.5 cycle for replicates of the same cDNA. The pattern of pr-10 expression was the same when normalized to either $18 \mathrm{~S}$ or actin. Data are mean expression levels of pr-10 normalized to actin.

Overexpression of ZmPR-10 in $E$. coli and partial purification. The correct in-frame fusion of the pET28c-PR-10 construct was transformed into an E. coli BL21 (DE3) expression host. The overexpressed ZmPR-10 was predicted to be $16.9 \mathrm{kDa}$, containing the full-length mature ZmPR-10 sequence (160 amino acid residues) without extra sequence from the vector. Isopropyl$\beta$-D-thiogalactopyranoside induction of $p r-10$ expression and E. coli cell disruption were performed as previously described (12). Cell disruption and fractionation were performed at $4^{\circ} \mathrm{C}$. Inclusion bodies, which contained mainly the overexpressed ZmPR10 , then were recovered and resuspended in $100 \mathrm{ml}$ of $50 \mathrm{mM}$ Tris- $\mathrm{HCl}(\mathrm{pH} 8.0)$ containing $6 \mathrm{M}$ urea. Urea-soluble proteins then were separated from the urea-insoluble fraction by centrifugation $(18,000 \times g, 20 \mathrm{~min})$ and used to refold into the active form as described previously (12). The purity of the protein then was assessed by using sodium dodecyl sulfate-polyacrylamide gel electrophoresis (SDS-PAGE) according to the method of Laemmli (29) before storage in aliquots at $-70^{\circ} \mathrm{C}$. The content of overexpressed ZmPR-10 in each fraction was quantified with a BioRad GS-700 gel densitometer.

Nucleic acid degradation assay. The refolded $17-\mathrm{kDa} \mathrm{ZmRP}-$ 10 protein $(2 \mu \mathrm{g})$ isolated from $E$. coli was incubated with $15 \mu \mathrm{g}$ $(2 \mu \mathrm{g} / \mu \mathrm{l}$ in $10 \mathrm{mM}$ Tris-HCl, $\mathrm{pH} 8.0,1 \mathrm{mM}$ EDTA) of total RNA from yeast (Sigma-Aldrich), A. flavus, and calf (Sigma) for $5 \mathrm{~h}$ at $37^{\circ} \mathrm{C}$. At the end of incubation, the protein was removed by extraction with phenol-chloroform and the nucleic acids were separated on $1.2 \%$ agarose gels and stained with $0.003 \%$ ethidium bromide (2). The brighter the intensity of the stained RNA samples, the less RNA degradation and, therefore, the lower the RNase activity. Controls include RNA treated with sterile water, with proteins from noninduced $E$. coli cells, or with heatinactivated purified ZmPR-10 protein from E. coli.

In vitro antifungal activity assay of $\mathrm{ZmPR}-10$. The antifungal activity of overexpressed ZmPR-10 against the growth of phytopathogenic fungi, such as $A$. flavus and $V$. dahliae, was assayed in $10 \%$ potato dextrose broth (PDB) (Difco Laboratories, Detroit) using microtiter plates as described previously (13). Seven-day-old A. flavus conidia or $V$. dahliae microconidia were allowed to germinate and grow in the presence of $10 \%$ PDB supplemented with overexpressed $\mathrm{ZmPR}-10$ at concentrations ranging from 5 to $400 \mu \mathrm{g} / \mathrm{ml}$ at $30^{\circ} \mathrm{C}$ (A. flavus) or $22^{\circ} \mathrm{C}$ (V. dahliae) for $24 \mathrm{~h}$. The negative control was $10 \mathrm{mM}$ phosphate buffer $(\mathrm{pH} 7.0)$ containing heat-inactivated proteins at a concentration of $100 \mu \mathrm{g} / \mathrm{ml}$. The hyphal growth of control or treated fungi was examined after 8 and $24 \mathrm{~h}$ of incubation under a microscope as previously described (13), and at least 40 measurements of hyphal length were taken for each treatment. The data presented here were combined from two repeated experiments.

Tobacco transformation. The pBI121-dS35-PR-10 construct was transformed into electrocompetent Agrobacterium tumefaciens LBA4404 (Gibco-BRL, Bethesda, MD) via electroporation using a Cell-Porator (Bio-Rad, Hercules, CA) according to the manufacturer's instruction. The transformation of tobacco (Nicotiana tabacum L. cv. SR-1) leaf disks and the selection and regeneration of transgenic tobacco plants expressing the maize $\mathrm{pr}$ 10 gene were done according to the procedures described by Horsch et al. (23).

Confirmation of pr-10 transformation and expression. PCR of the maize $p r-10$ gene from genomic DNA of transgenic tobacco leaves was performed with primers spanning from within the d35S promoter (5'-ATGACGCACAATCCACTATCCT-3') (d35SFor) to the $3^{\prime}$ end of the pr-10 gene (PR-10-Sac I) using AmpliTaq Gold polymerase (Stratagene, La Jolla, CA). PCR products were analyzed by gel electrophoresis.

Real-time RT-PCR was used to examine the transcript level of pr-10. Total RNA was isolated from tobacco leaves of seven transgenic plants that were confirmed to have the gene, reversetranscribed, and amplified as described above. In addition to $18 \mathrm{~S}$, the expression of actin also was determined and used as an internal control. The pattern of $p r-10$ expression was the same when normalized to either $18 \mathrm{~S}$ or actin. This experiment was conducted twice, each time with two replicates. The level of $p r-10$ expression presented in this article is the mean value (combined from two repeated experiments) normalized to the level of actin.

Antifungal assays of transgenic tobacco plants. Leaves from selected transgenic (numbers 4,2 , and 5, which express maize $p r$ 10 at high, medium, and low levels, respectively), and control (number 8) tobacco plants (transformed with pBI121) were ground with liquid $\mathrm{N}_{2}$ with no buffer added. Ground tissues then were centrifuged at $8,200 \times g$ for $10 \mathrm{~min}$ at room temperature to collect leaf extract from each sample. The total protein concentration of the leaf extracts of different samples ranged from 0.27 to $0.34 \mathrm{mg} / \mathrm{ml}$; each was adjusted to $0.27 \mathrm{mg} / \mathrm{ml}$ for the antifungal assay. Conidia ( $25 \mu \mathrm{l}$ of $10^{5} \mathrm{conidia} / \mathrm{ml}$ ) then were added to $225 \mu \mathrm{l}$ of plant extracts containing $\approx 60 \mu \mathrm{g}$ of total protein, mixed, and incubated for $12 \mathrm{~h}$ at $30^{\circ} \mathrm{C}($ A. flavus $)$ or $22^{\circ} \mathrm{C}(\mathrm{V}$. dahliae $)$ in a 12-well macrotiter plate (7). At the end of incubation, fungal hyphal growth then was examined under a microscope as previously described (13) and measurements of at least 40 individual hyphae were taken for each treatment. The data presented here were combined from two repeated experiments.

Statistical analysis. All data were analyzed using the analysis of variance procedure of the Statistical Analysis System (SAS Institute, Cary, NC). Mean separations for $p r-10$ expression in 
maize kernels during different developmental stages and in transgenic tobacco leaf tissues were performed using the method of Duncan's multiple range test $(P \leq 0.05)$.

\section{RESULTS}

Protein identification. Endosperm proteins from three resistant and three susceptible maize genotypes were compared using proteomics. Gel analysis of differential protein expression between resistant and susceptible genotypes identified one protein (\#717), with expression fivefold higher in resistant genotypes GTMAS:gk, Mp420 and Mp313E than in susceptible maize lines Mo17, B73, and Va35 (Fig. 2). This protein, with an estimated molecular weight (MW) of $15.86 \mathrm{kDa}$ and a $\mathrm{pI}$ of 5.30, was recovered from Coomassie brilliant blue R-250-stained preparative 2-D gels and subjected to in-gel trypsin digestion. The digested peptides then were sequenced using ESI-MS/MS (Fig. 3). The peptide sequences obtained from MS were shown in the inset of Figure 3. Peptide sequences of \#717 matched portions of PR-10 from sorghum (T14718), and are highly homologous to a portion of intracellular pathogenesis-related proteins from asparagus (Asparagus officinalis, CAA10720), lily (Lilium longiflorum, AAF21625), and white lupin (Lupinus albus, AJ000108) (LaPR10).

Cloning of $p r-10$ gene from maize and sequence homology analysis. A $0.4-\mathrm{kb}$ PCR product was obtained from a maize endosperm cDNA library made from Ohio 43 immature kernels of 10 to 14 DAP after two rounds of PCR amplification using two degenerate primers. DNA sequencing of the cloned PCR product and homology of the deduced amino acid sequence to rice and sorghum PR-10 proteins confirmed that it is part of the pr-10 gene. The $5^{\prime}$ and $3^{\prime}$ ends of the $p r-10$ gene were cloned by RACE, revealing a complete cDNA of $620 \mathrm{bp}$ with an open reading frame for 160 amino acids, with a calculated MW and $\mathrm{pI}$ of $16.9 \mathrm{kDa}$ and 5.38, respectively (Fig. 4). These values are similar to those determined from 2-D gels. Cloning of the corresponding genomic DNA (713 bp) also revealed the presence of an intron of $93 \mathrm{bp}$ (Fig. 4). The sequence has been deposited into GenBank under accession no. AY953127. The deduced ZmPR-10 sequence does not appear to contain a signal peptide sequence according to predication by SignalP 3.0 Server, which agrees with previous reports that PR-10 is an intracellular protein (24). The protein is also quite hydrophilic, with only one possible membranespanning helix based on the hydrophobicity distribution analysis.

The homology search of the deduced amino acid sequence of ZmPR-10 showed that it shares 81.4 and $85.6 \%$ identity with PR10 protein from sorghum and rice, respectively (Fig. 5), which confirmed the identity of the cloned gene. It also showed $51.9 \%$ identity to intracellular pathogenesis-related proteins from lily (AAF21625), and asparagus (CAA10720), and $\approx 30$ to $35 \%$ identity to a pathogenesis-related protein from white lupin (AJ000108), a ribonuclease from ginseng (P80890) (33), and major food allergens of celery (S30055) (3) and apple (T17007) (22) (Fig. 5).

A BLAST homology search of maize ESTs identified two maize ESTs (AI812193 and BM073462) whose deduced amino acid sequences showed a complete match to the deduced peptide sequence of the cloned $p r-10$ cDNA, and three additional ESTs (CK367898, BI643519, and CF630679) with only one mismatch in the peptide sequence with Zm-PR-10. The pr-10 cDNA had only one nucleotide difference in the overlapping region with BM073462, its closest match.

Temporal expression of $p r-10$ in maize with or without fungal infection. The transcript level of $p r-10$ increases significantly during early kernel development in noninfected plants, with a fivefold increase in the 15-day period (7 to 22 DAP) in both resistant (GT-MAS:gk) and susceptible (Mo17) genotypes (Fig. 6). However, the pr-10 transcript level was higher in the noninfected Mo17 kernels than that in GT-MAS:gk (significant at day 3 and 15). Upon Aspergillus flavus infection, the expression of $\mathrm{pr}$-10 was upregulated significantly at day 8 and 15 in GTMAS:gk, whereas its expression remained the same or decreased at day 8 and 15 in the susceptible genotype compared with noninfected control kernels (Fig. 6). The expression of $p r-10$ did not change significantly in the wound-only controls compared with the nonwounded controls at the same stage (Fig. 6).

Expression of pr-10 in $\boldsymbol{E}$. coli. After $3 \mathrm{~h}$ of induction, the level of ZmPR-10 was $\approx 35 \%$ of total E. coli cell proteins (Fig. 7, lane $3)$. However, the majority of ZmPR-10 protein was not soluble in

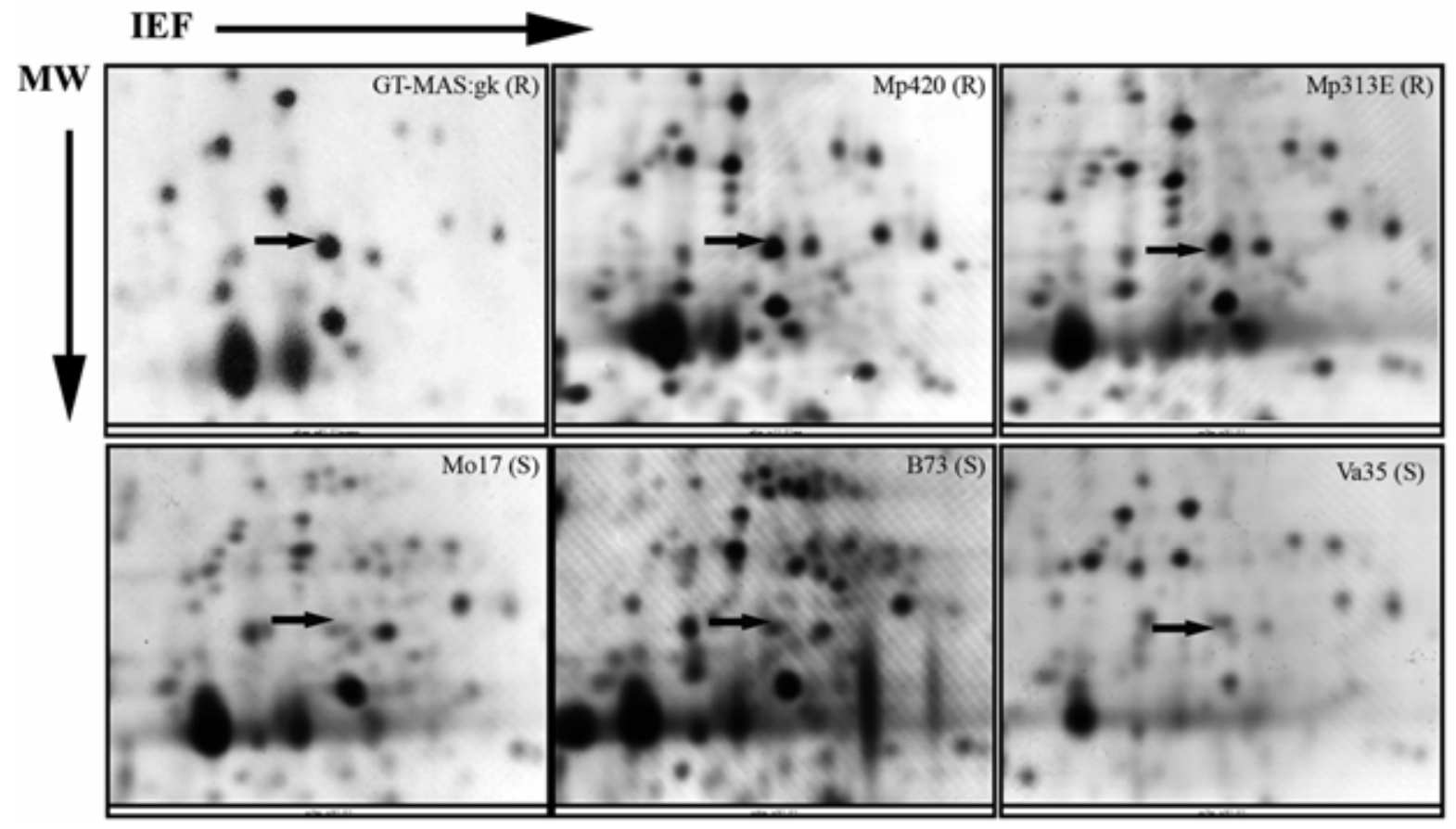

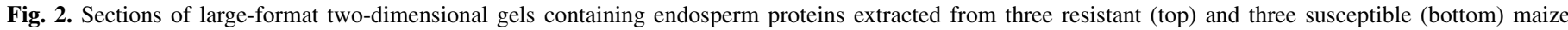

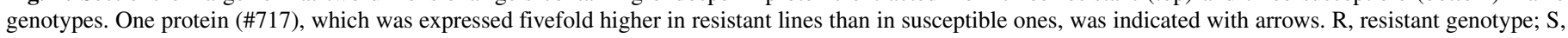
susceptible genotype. 
water or low salt buffers and remained in the pellet, although it became soluble in the presence of $6 \mathrm{M}$ urea (Fig. 7). By taking advantage of this characteristic, ZmPR-10 protein was significantly enriched (accounting for $85 \%$ of urea-soluble protein) in urea-soluble protein fraction (Fig. 7, lane 5). Urea then was removed slowly through dialysis in the presence of cystamine to allow protein refolding. This refolded protein fraction contains mainly the 17-kDa ZmPR-10 and a few minor proteins (Fig. 7, lane 7). These minor proteins are possible breakdown products or multimers of ZmPR-10, as has been previously observed (12), because none of these protein bands were present in the control protein sample refolded from a urea-soluble fraction of noninduced E. coli cells (Fig. 7, lane 8).

RNase activity of overexpressed ZmPR-10 protein. The above overexpressed and refolded ZmPR-10 protein demonstrated RNase activity in in vitro assays against yeast RNA. The RNase activity was abolished when the refolded ZmPR-10 was incubated at $80^{\circ} \mathrm{C}$ for $15 \mathrm{~min}$ (data not shown), confirming that the ribonucleolytic activity is of a protein origin. Less than $10 \%$ of total RNase specific activity was detected in the control sample prepared from noninduced $E$. coli cells or in the nonfolded preparations compared with the refolded ZmPR-10. The ZmPR-10 protein also was active in vitro against RNAs isolated from $A$. flavus and calf (data not shown).

In vitro antifungal activities of ZmPR-10 from $\boldsymbol{E}$. coli. This partially purified and refolded ZmPR-10 protein also exhibited an inhibitory effect in vitro on conidia germination and hyphal growth of A. flavus. The A. flavus conidia treated with ZmPR-10 at $100 \mu \mathrm{g} / \mathrm{ml}$ showed delayed germination and slower hyphal growth once they germinated compared with the control treated with heat-inactivated ZmPR-10. The mean hyphal length of control culture and treated culture was $67.8 \pm 12.6 \mu \mathrm{m}$ (standard error) and 0 (not germinated yet) at $8 \mathrm{~h}$, and $194.7 \pm 31.1$ and $76.9 \pm 14.5 \mu \mathrm{m}$ at $24 \mathrm{~h}$, respectively (Fig. 8). The $50 \%$ inhibition of fungal growth compared with the control was achieved in the presence of $\mathrm{ZmPR}-10$ at $80 \mu \mathrm{g} / \mathrm{ml}(4.73 \mu \mathrm{M})$. The inhibitory

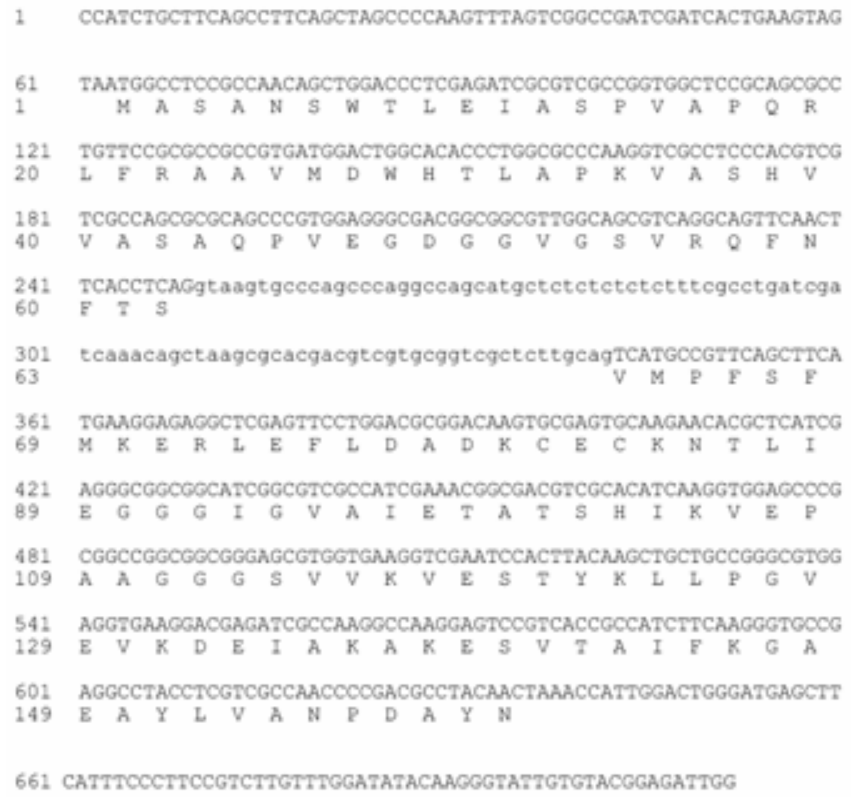

Fig. 4. DNA sequence and deduced amino acid sequences of ZmPR-10. cDNA of pr-10 was cloned based on peptide sequences, and its corresponding genomic DNA cloned by polymerase chain reaction contains an intron of 93 bp (lowercase).

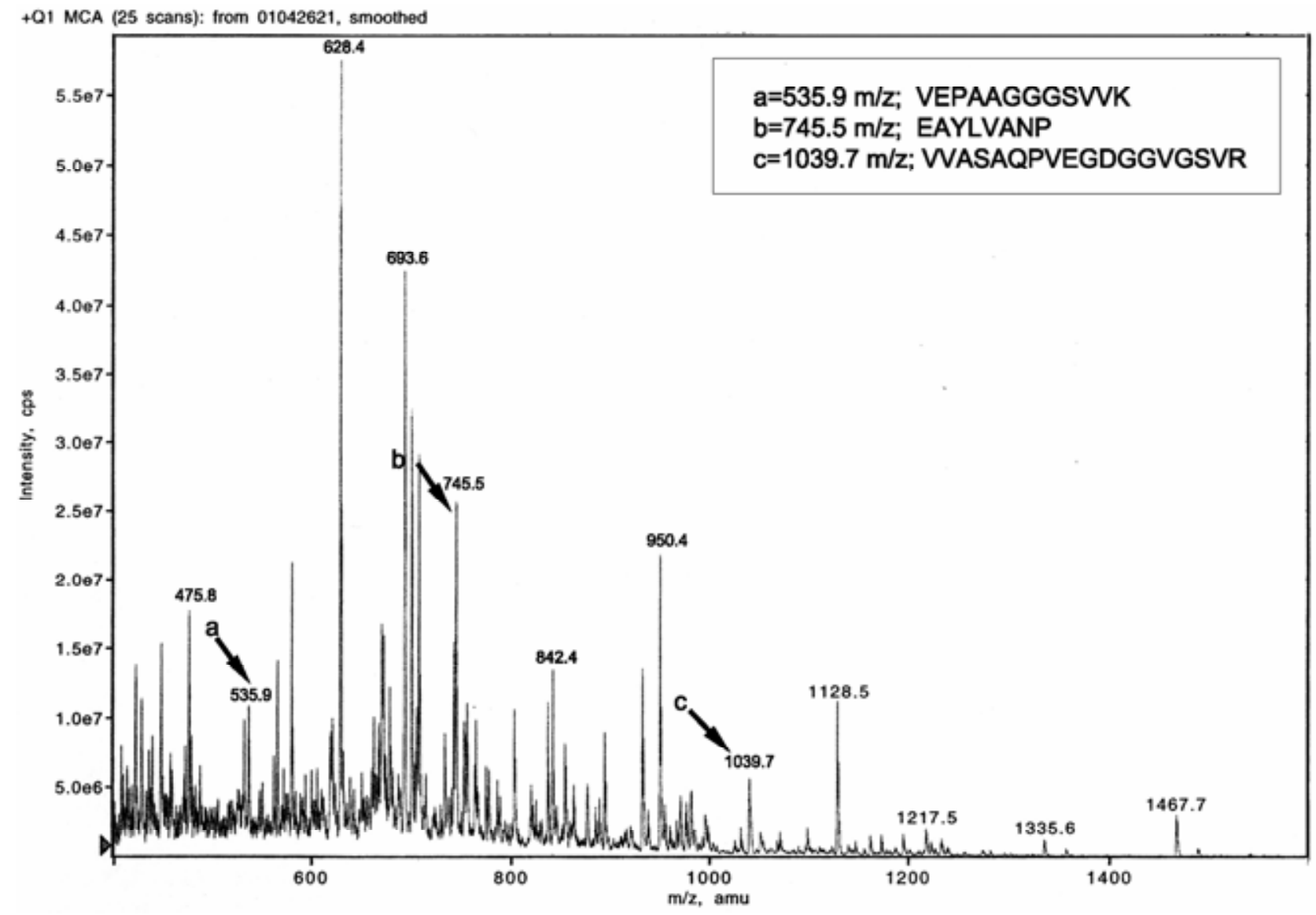

Fig. 3. Electrospray ionization peptide mass spectrum of a peptide mixture from in-gel tryptic digestion of protein \#717. Peptide sequences corresponding to peaks $\mathrm{a}, \mathrm{b}$, and $\mathrm{c}$ are shown in the inset; " $\mathrm{m} / \mathrm{z}$ " stands for mass to charge ratio. 
effect on A. flavus was observed in the presence of as low as $25 \mu \mathrm{g}$ of protein per milliliter (data not shown). It also was noticed that A. flavus is less sensitive to ZmPR-10 than V. dahliae, which requires approximately half as much protein to see the same growth inhibition effect (data not shown).

Transgenic tobacco expressing maize pr-10. Twenty tobacco leaf disks were infected with Agrobacterium tumefaciens containing the pBI121-d35S-PR-10-nos construct (Fig. 1), and seven plants regenerated from seven independent transformation events were selected and tested for the presence of maize $p r-10$ gene using PCR. A 0.7-kb PCR product was amplified from genomic DNAs of all seven transformants, and DNA sequencing of the PCR product confirmed the presence of maize $p r-10$ gene (data not shown).

The expression level of maize $p r-10$ gene relative to actin in transgenic tobacco leaves varies among the seven transformants (Fig. 9). The highest level of pr-10 expression was detected in plant number 4 which was approximately five times the level of that in plant number 5, the lowest level of pr-10 expression among the seven transformants (Fig. 9). No pr-10 expression was detected in the control plant number 8 transformed with pBI121 vector (Fig. 9). It is interesting to note that leaf extracts from those plants that had high levels of $p r-10$ expression also demonstrated high level of RNase activities against yeast RNA in in vitro assays (data not shown).

Antifungal properties of transgenic tobacco plants. An increase in antifungal activity against Aspergillus flavus growth was observed in the leaf extracts of transgenic tobacco plants expressing maize $p r-10$ gene compared with the control leaf extract. The strongest inhibition on fungal hyphal growth was observed in conidia treated for $12 \mathrm{~h}$ with leaf extracts from plant number 4 with a mean hyphal length of $46.5 \pm 3.8 \mu \mathrm{m}$ (standard error), compared with that treated with leaf extract from the control plant (plant number 8) with a mean hyphal length of $135.6 \pm 7.8 \mu \mathrm{m}$. Leaf extract from plant number 2, which showed an intermediate level of $p r-10$ expression, also demonstrated significant inhibition of fungal hyphal growth $(66.8 \pm 3.8 \mu \mathrm{m})$ when compared with the control. The leaf extract from plant number 5, which had the lowest level of $p r-10$ expression among the seven transformants, exhibited a level of inhibition on fungal growth $(78.2 \pm 4.7 \mu \mathrm{m})$ similar to that observed for plant number 2 , and both were significantly different compared with the control based on the mean hyphal length of $A$. flavus.

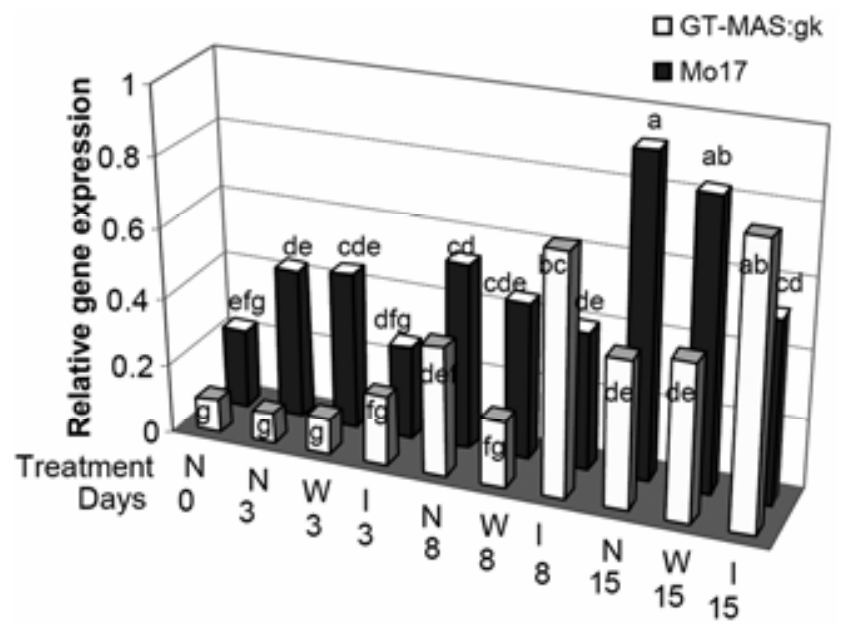

Fig. 6. Expression of pathogenesis-related (PR) protein 10 gene during kernel developmental stages with or without Aspergillus flavus infection in maize. Maize ears were inoculated 7 days after pollination. Transcript levels of $p r-10$ gene were measured at $0,3,8$, and 15 days after inoculation using real-time reverse-transcriptase polymerase chain reaction and are expressed as relative to actin (internal normalizer) in both resistant (GT-MAS:gk, light bar) and susceptible (Mo17, dark bar) maize genotypes. N, nonwounded and noninoculated controls; W, wounded only; and I, inoculated. The bars labeled with the same letters are not statistically different within and across the genotypes based on Duncan's multiple range test.

1

Maize MASANSWTLE IASPVAPQRL FRAAVMWHT LA-PKVASHV VASAQPVEGD

Rice MASTNSWTHE IESPVAAPRL FRAAVMDWHT LA-PKIASHI I $\overline{\text { VASAHPVDGD }}$

Sorghum MASANSWTLE IPSPVAARRL FCAAVTPWHP RSTPKVNSHV VASAHPVEDD

-GGVGSVRQF NFTS-VMPFS FMKERLEFLD ADKCECKNTL

Aspara

Lily

Lupin MSSGSWSHE VAVNVAAGRL FKAAMLDWHN LG-PKIVPDF ISSGSVVSGD GSVGSVRQF NFTS-AMPFS HMKERLEFLD VDKCECKSTL MGVFNYEAE TTSVIPAARL FKSYVLDGDK LI-PKVAPQA ITSVENVEGN -GGPGTIKNI TFGE-GSRYK YVKERVDEVD NTNFTYSYTV

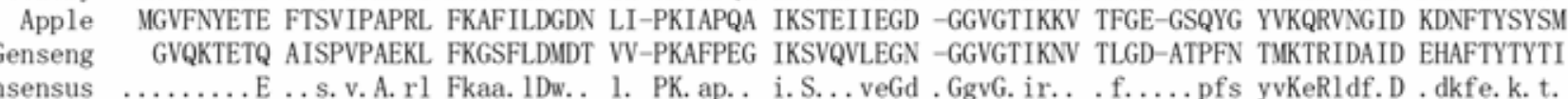

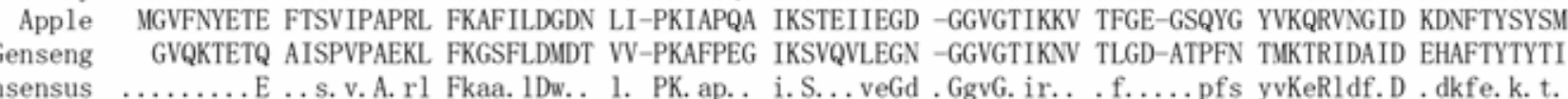

Consensus ........E ... s. v. A. rl Fkaa. 1Dw.. 1. PK. ap.. i.S...veGd.GgvG. ir.. .f.....pfs yvKeRldf. D . dkfe.k. t.

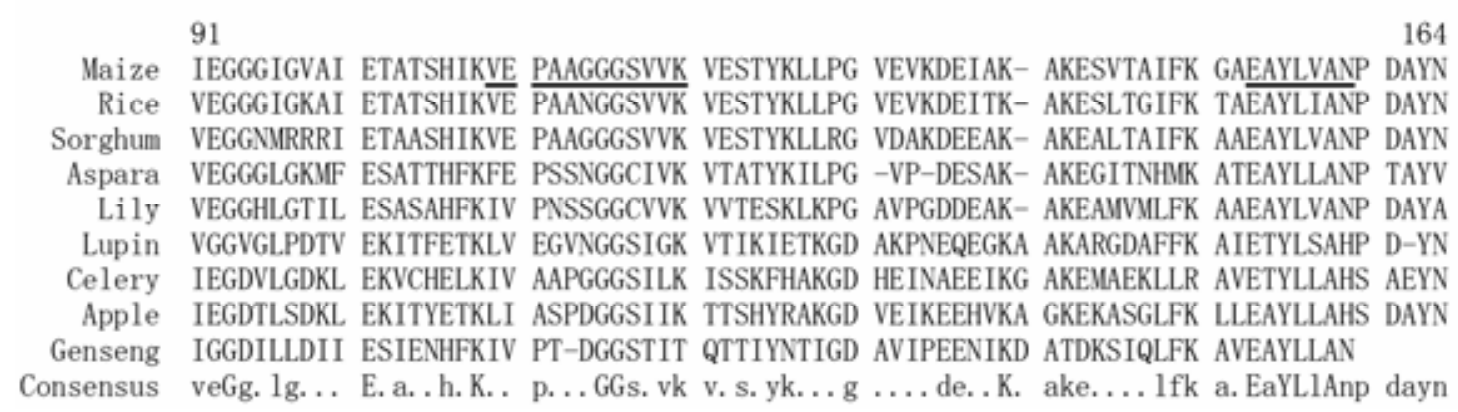

Fig. 5. Sequence homology comparisons of deduced amino acid sequences of pathogenesis-related protein PR-10 from Zea mays (this study, accession number AY953127, Maize) with a jasmonate inducible PR protein from Oryza sativa (AAL74406, Rice) (26), a PR protein from Sorghum bicolor (T14718, Sorghum) (30), an intracellular PR protein, PR-106, from Lilium longiflorum (AAF21625, Lily) (24), an intracellular PR protein, isoform 6, from Asparagus officinalis (CAA10720, Aspara.), a PR protein from Lupinus albus (AJ000108, Lupin) (2), and a ginseng ribonuclease (P80890, Ginseng) (33), as well as major food allergens of celery (S30055) (3) and apple (T17007) (22). The underlined letters indicate the region where the peptide sequence was obtained from electrospray ionization tandem mass spectrometry of spot \#717. Gaps (indicated with "-") were introduced to achieve maximum sequence alignment. The consensus sequence is shown in the bottom of the alignment. Uppercase letters in the consensus sequence indicate identical amino acid residues at the same position in most sequences, lowercase letters indicate highly conserved amino acid residues, and "." indicates low or no amino acid consensus at that position. 


\section{DISCUSSION}

Comparative investigations of maize genotypes resistant or susceptible to A. flavus infection and aflatoxin production have demonstrated the existence of two levels of kernel resistance strategically distributed on the kernel surface (e.g., physical barrier, kernel wax and cutin layer) and inside kernels (e.g., proteins) (15) Recent work determined that both constitutive and induced kernel proteins are required for resistance to aflatoxin production (8), and that one distinct difference between resistant and susceptible lines is the higher level of constitutive expression of antifungal, stress-related, and highly hydrophilic storage proteins in the former, in both the endosperm and embryo $(9,10)$. In the present study, one such protein (\#717), significantly upregulated in the endosperm of resistant lines compared with susceptible ones as revealed through 2-D gel comparisons, was identified and further investigated. The peptide sequence homology analysis identified this protein as PR-10. Because ZmPR-10 is present in mature kernels, it should be called ZmPR-10-like protein according to the definition of PR proteins (43). However, in this study, it is referred to merely as ZmPR-10 protein for simplicity.

Currently, PR proteins are grouped into 17 independent families, PR-1 to PR-17, and antifungal activities have been described for some $(16,44)$. PR-10s have been reported in a number of plant species, including asparagus (45), lily (24), and rice (32). They also share sequence similarities to major food allergens of celery (3) and apple (22), and to a ginseng ribonuclease (33). For this reason, intracellular PR-10s also are classified as RNase-like proteins (43). In the present study, the corresponding cDNA encoding ZmPR-10 was cloned, and it showed significant sequence homology to proteins from the PR-10 family, including one from white lupin that has been shown to possess RNase activity (2).

Evidence linking PR-10 to host resistance has been reported. A barley $p r-10$ gene was found to be specifically induced in the epidermis of resistant cultivars upon infection by Rhynchosporium secalis, but not in leaf tissues of near-isogenic susceptible plants (40). In cowpea, a pr-10 homolog was specifically upregulated in resistant epidermal cells inoculated with the rust fungus Uromyces vignae Barclay (34). Also, in rice, a pr-10 transcript was induced during infection with Magnaporthe grisea (31) or by salicylic or jasmonic acid applications to rice plants $(25,31)$.

In the present study, the involvement of $\mathrm{ZmPR}-10$ in host resistance against $A$. flavus infection and aflatoxin production was first supported by evidence obtained through proteome analysis of

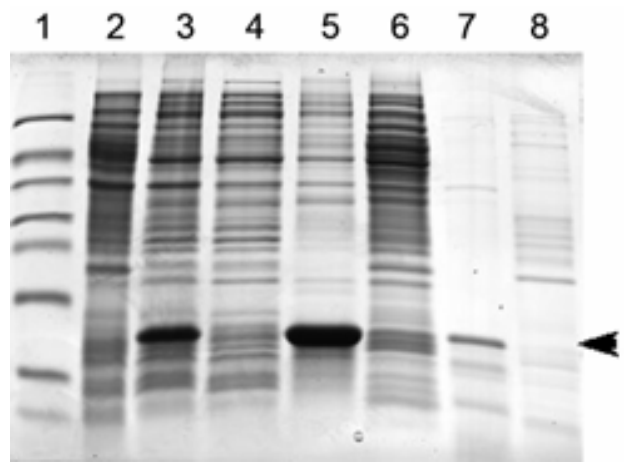

Fig. 7. Overexpression of maize gene pr-10 in Escherichia coli and partial purification of its protein. Lane 1, MW marker; lane 2, total cell protein from noninduced $E$. coli cells; lane 3, total cell protein from isopropyl- $\beta$-D-thiogalactopyranoside-induced $E$. coli cells (the overexpressed protein represents $\approx 30 \%$ of total cell proteins); lane 4 , water- or salt-soluble protein fraction from induced cells; lane 5, urea-soluble protein fraction from induced cells; lane 6, urea-soluble protein from noninduced $E$. coli cells; lane 7, refolded ZmPR-10 protein from induced urea-soluble fraction; and lane 8, proteins refolded from urea-soluble fraction of noninduced $E$. coli cells. mature kernels demonstrating higher constitutive expression of PR-10 in resistant versus susceptible lines. Supporting evidence also includes developmental expression of its corresponding gene after fungal inoculation, and antifungal activity of both the protein overexpressed in E. coli and the transgenic tobacco leaf extracts. During development, the $p r-10$ transcript level was observed to be higher in susceptible Mo17 kernels than in the resistant GTMAS:gk uninoculated plants (at days 3 and 15). However, this higher transcript level during development in the susceptible genotype did not lead to a higher constitutive protein level (as was observed through proteomics) in mature kernels, the target of aflatoxin accumulation. It should be kept in mind that it is the proteins themselves, not the corresponding transcripts, that are involved in biological functions (e.g., antifungal activity).

Overexpressed ZmPR-10 was found to be inhibitory to both A. flavus hyphal growth and conidia germination. Based on the $\mathrm{IC}_{50}$ value, ZmPR-10 is slightly less potent than the previously described $14-\mathrm{kDa}$ TI protein (12). Similar inhibitory effects also were observed when the leaf extracts of transgenic tobacco plants expressing maize $p r-10$ gene were used in in vitro bioassays. However, the level of $p r-10$ expression in transgenic tobacco appears to be much lower than that observed in developing maize kernels based on data from real-time RT-PCR.

The partially purified and refolded ZmPR-10 from E. coli demonstrated, in vitro, a clear RNase activity against RNAs, not only from fungi (yeast and $A$. flavus) but also from an animal (calf

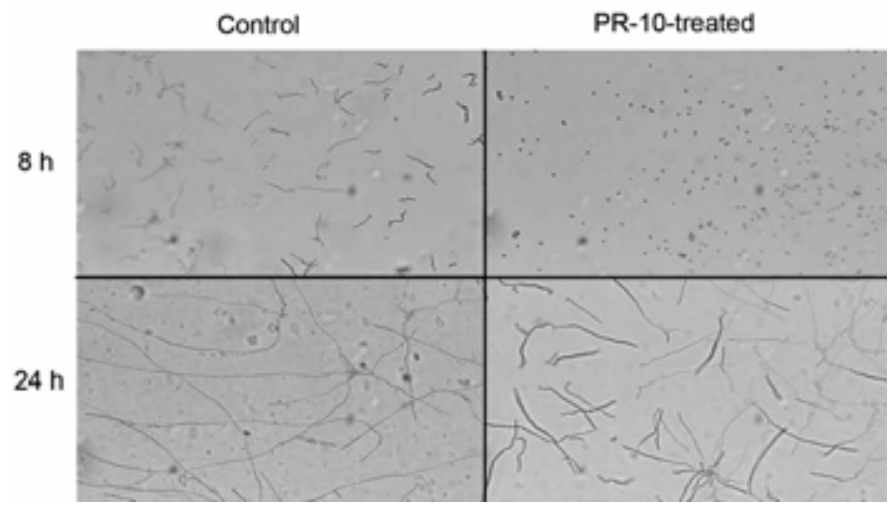

Fig. 8. Antifungal bioassay of ZmPR-10 protein. Aspergillus flavus conidia were germinated in $10 \%$ potato dextrose broth medium containing refolded ZmPR-10 at $100 \mu \mathrm{g} / \mathrm{ml}$ (right) or heat-inactivated ZmPR-10 at $100 \mu \mathrm{g} / \mathrm{ml}$ to serve as controls (left) for 8 (top) and $24 \mathrm{~h}$ (bottom) at $30^{\circ} \mathrm{C}$.

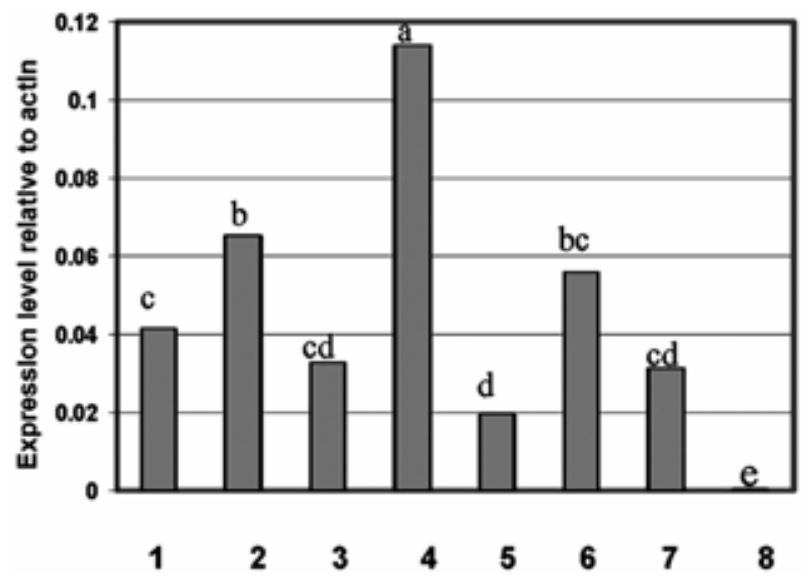

Fig. 9. Expression of the maize $p r-10$ gene in the leaves of transgenic tobacco plants. The $p r-10$ expression in transgenic (numbers 1 to 7 ) tobacco leaf tissues is reported as the ratio relative to the level of actin in the control plant transformed with pBI121 vector only (number 8) The bars labeled with the same letters are not statistically different based on Duncan's multiple range test. 
tRNA). In addition, several transgenic tobacco plants expressing maize $p r-10$ also showed an increase in RNase activities compared with a vector-only transformed control plant. This is the first reported demonstration of RNase activity of a PR-10 protein from a crop. Furthermore, leaf extracts from plants expressing high levels of $p r-10$ also showed high levels of RNase activities against yeast RNA in in vitro assays. In addition, the leaf extract from plant number 2, expressing the highest level of pr-10, demonstrated the strongest inhibition of A. flavus hyphal growth in in vitro assays. However, the linkage between PR-10 RNase activity and its antifungal activity (inhibition on fungal growth) is not understood. The involvement of plant RNase activity in defense against pathogen infection and resistance has been reported in tobacco (20). An increase in the extracellular RNase activity and enhanced resistance were observed after tobacco was challenged with Phytophthora parasitica var. nicotianae. This protection was found to be durable and effective against other unrelated pathogens.

One speculation concerning RNase activity in resistance is that it may function in determining the compatibility reactions during the interaction of the host and pathogen, similar to the role proposed for the PR-10 homologs as self-incompatibility determinants in pollen. It has been proposed in cases of pollen incompatibility reactions between plants that some PR-10 homologs play a role in the recognition of pollen grains by inducing an inhibition reaction on the stigma surface $(5,38)$.

The relationship between ZmPR-10's RNase activity and maize kernel aflatoxin resistance still needs much clarification. The findings of the present study do suggest, however, that ZmPR-10 protein is a component of the constitutive defense arsenal of the maize plant.

\section{ACKNOWLEDGMENTS}

This study was supported by USDA cooperative agreement 58-6435-2130 and USDA National Research Initiative Competitive Grant 200235201-12541. We thank C. Ambrogio, D. Hadrick, and J. Veal for technical assistance; and H.-J. Kim, K. Ehrlich, and G. Windham for critical reviewing of the manuscript.

\section{LITERATURE CITED}

1. Altschul, S. F., Madden, T. L., Schäffer, A. A., Zhang, J.-H., Zhang, Z., Miller, W., and Lipman, D. J. 1997. Gapped BLAST and PSI-BLAST: A new generation of protein database search programs. Nucleic Acids Res. 25:3389-3402.

2. Bantignies, B., Seguin, J., Muzac, I., Dedaldechamp, F., Gulick, P., and Ibrahim, R. 2000. Direct evidence for ribonucleolytic activity of a PR-10like protein from white lupin roots. Plant Mol. Biol. 42:871-881.

3. Breiteneder, H., Ferreira, F., Hoffmann-Sommergrube, K., Ebner, C., Breitenbach, M., Rumpold, H., Kraft, D., and Scheiner, O. 1993. Four recombinant isoforms of Cora a 1, the major allergen of hazel pollen, show different IgE-binding properties. Eur. J. Biochem. 212:355-362.

4. Brown, R. L., Chen, Z.-Y., Cleveland, T. E., and Russin, J. S. 1999. Advances in the development of host resistance to aflatoxin contamination by Aspergillus flavus. Phytopathology 89:113-117.

5. Bufe, A., Schramm, G., Keown, M. B., Schlaak, M., and Becker, W. M. 1995. Major allergen $\mathrm{Phl} \mathrm{p} \mathrm{Vb}$ in timothy grass is a novel pollen RNase. FEBS Lett. 363:6-12.

6. Campbell, K. W., and White, D. G. 1995. Evaluation of corn genotypes for resistance to Aspergillus ear rot, kernel infection, and aflatoxin production. Plant Dis. 79:1039-1045.

7. Cary, J. W., Rajasekaran, K., Jaynes, J. M., and Cleveland, T. E. 2000. Transgenic expression of a gene encoding a synthetic antimicrobial peptide results in inhibition of fungal growth in vitro and in planta. Plant Sci. 154:171-181.

8. Chen, Z.-Y., Brown, R. L., Cleveland, T. E., Damann, K. E., and Russin, J. S. 2001. Comparison of constitutive and inducible maize kernel proteins of genotypes resistant or susceptible to aflatoxin production. J. Food Prot. 64:1785-1792.

9. Chen, Z.-Y., Brown, R. L., Damann, K. E., and Cleveland, T. E. 2002. Characterization of an endosperm protein expressed at higher levels in maize genotypes resistant to Aspergillus flavus infection/aflatoxin production. (Abstr.) Phytopathology 92(suppl.):S15.
10. Chen, Z.-Y., Brown, R. L., Damann, K. E., and Cleveland, T. E. 2002. Identification of unique or elevated levels of kernel proteins in aflatoxin-resistant maize genotypes through proteome analysis. Phytopathology 92:1084-1094.

11. Chen, Z.-Y., Brown, R. L., Damann, K. E., and Cleveland, T. E. 2004. Identification of a maize kernel stress-related protein and its effect on aflatoxin accumulation. Phytopathology 94:938-945.

12. Chen, Z.-Y., Brown, R. L., Lax, A. R., Cleveland, T. E., and Russin, J. S. 1999. Inhibition of plant-pathogenic fungi by a corn trypsin inhibitor overexpressed in Escherichia coli. Appl. Environ. Microbiol. 65:1320-1324.

13. Chen, Z.-Y., Brown, R. L., Lax, A. R., Guo, B. Z., Cleveland, T. E., and Russin, J. S. 1998. Resistance to Aspergillus flavus in corn kernels is associated with a 14-kDa protein. Phytopathology 88:276-281.

14. Chen, Z.-Y., Brown, R. L., Russin, J. S., Lax, A. R., and Cleveland, T. E. 1999. A corn trypsin inhibitor with antifungal activity inhibits Aspergillus flavus $\alpha$-amylase. Phytopathology 89:902-907.

15. Chen, Z.-Y., Cleveland, T. E., Brown, R. L., Bhatnagar, D., Cary, J. W., and Rajasekaran, K. 2002. Corn as a source of antifungal genes for genetic engineering of crops for resistance to aflatoxin contamination. Pages 131-150 in: Crop Biotechnology. K. Rajasekaran, J. W. Finley, and T. J. Jacks, eds. ACS Symposium Series No. 829, American Chemical Society, Washington, DC

16. Christensen, A. B., Cho, B. H. O., Naesby, M., Gregersen, P. L., Brandt, J., Madriz-Ordeñana, K., Collinge, D., and Thordal-Christensen, H. 2002. The molecular characterization of two barley proteins establishes the novel PR-17 family of pathogenesis-related proteins. Mol. Plant Pathol. 3:135-144.

17. Cordero, M. J., Raventós, D., and San Segundo, B. 1992. Induction of PR proteins in germinating maize seeds infected with the fungus Fusarium moniliforme. Physiol. Mol. Plant Pathol. 41:189-200.

18. Cordero, M. J., Raventos, D., and San Segundo, B. 1994. Differential expression and induction of chitinases and $\beta-1,3$-glucanases in response to fungal infection during germination of maize seeds. Mol. PlantMicrobe Interact. 7:23-31.

19. Diener, U. L., Cole, R. J., Sanders, T. H., Payne, G. A., Lee, L. S., and Klich, M. A. 1987. Epidemiology of aflatoxin formation by Aspergillus flavus. Annu. Rev. Phytopathol. 25:249-270.

20. Galiana, E., Bonnet, P., Conrod, S., Keller, H., Panabières, F., Ponchet, M., Poupet, A., and Ricci, P. 1997. RNase activity prevents the growth of a fungal pathogen in tobacco leaves and increases upon induction of systemic acquired resistance with elicitin. Plant Physiol. 115:1557-1567.

21. Guo, B. Z., Russin, J. S., Cleveland, T. E., Brown, R. L., and Widstrom, N. W. 1996. Resistance to aflatoxin contamination in corn as influenced by relative humidity and kernel germination. J. Food Prot. 59:276-281.

22. Hoffmann-Sommergruber, K., Vanek-Krebitz, M., Radauer, C., Wen, J., Ferreira, F., Scheiner, O., and Breiteneder, H. 1997. Genomic characterization of members of the Bet $\mathrm{v} 1$ family: Genes coding for allergens and pathogenesis-related proteins share intron positions. Gene 197:91-100.

23. Horsch, R. B., Fry, J. E., Hoffmann, N. L., Rogers, S. G., and Fraley, R. T. 1985. A simple and general method for transferring genes into plants. Science 227:1229-1231.

24. Huang, J. C., Chang, F. C., and Wang, C. S. 1997. Characterization of a lily tapetal transcript that shares sequence similarity with a class of intracellular pathogenesis-related (IPR) proteins. Plant Mol. Biol. 34:681-686.

25. Huang, Z., White, D. G., and Payne, G. A. 1997. Corn seed proteins inhibitory to Aspergillus flavus and aflatoxin biosynthesis. Phytopathology 87:622-627.

26. Jwa, N. S., Agrawal, G. K., Rakwal, R., Park, C. H., and Agrawal, V. P. 2001. Molecular cloning and characterization of a novel jasmonate inducible pathogenesis-related class 10 protein gene, JIOsPR10,from rice (Oryza sativa L.) seedling leaves. Biochem. Biophys. Res. Commun. 286:973-983.

27. Kim, B. R., Nam, H. Y., Kim, S. U., Kim, S. I., and Chang, Y. J. 2003. Normalization of reverse transcription quantitative-PCR with housekeeping genes in rice. Biotechnol. Lett. 25:1869-1872.

28. Kiyosue, T., Yamaguchi-Shinozaki, K., and Shinozaki, K. 1994. Cloning of cDNAs for genes that are early responsive to dehydration stress in Arabidopsis thaliana L.: Identification of three ERDs as HSP cognate genes. Plant Mol. Biol. 25:791-798.

29. Laemmli, U. K. 1970. Cleavage of structural proteins during the assembly of the head of bacteriophage T4. Nature 227:680-685.

30. Lo, S. C., and Nicholson, R. L. 1998. Reduction of light-induced anthocyanin accumulation in inoculated sorghum mesocotyls. Implications for a compensatory role in the defense response. Plant Physiol. 116:979-989.

31. McGee, J. D., Hamer, J. E., and Hodges, T. K. 2001. Characterization of a PR-10 pathogenesis-related gene family induced in rice during infection with Magnaporthe grisea. Mol. Plant-Microbe Interact. 14:877-886.

32. Midoh, H., and Iwata, M. 1996. Cloning and characterization of a probenazole-inducible gene for an intracellular pathogenesis-related protein in rice. Plant Cell Physiol. 37:9-18. 
33. Moiseyev, G. P., Fedoreyeva, L. I., Zhuravlev, Y. N., Yasnetskaya, E., Jekel, P. A., and Beintema, J. J. 1997. Primary structures of two ribonucleases from ginseng calluses. New members of the PR-10 family of intracellular pathogenesis-related plant proteins. FEBS Lett. 407:207210.

34. Mould, M. J., Xu, T., Barbara, M., Iscove, N. N., and Heath, M. C. 2003. cDNAs generated from individual epidermal cells reveal that differential gene expression predicting subsequent resistance or susceptibility to rust fungal infection occurs prior to the fungus entering the cell lumen. Mol. Plant-Microbe Interact. 16:835-845.

35. Nichols, T. E., Jr. 1983. Economic impact of aflatoxin in corn. South. Coop. Ser. Bull. 279:67-71.

36. Oberschall, A., Deak, M., Torok, K., Sass, L., Vass, I., Kovacs, I., Feher, A., Dudits, D., and Horvath, G. V. 2000. A novel aldose/aldehyde reductase protects transgenic plants against lipid peroxidation under chemical and drought stresses. Plant J. 24:437-446.

37. Payne, G. A. 1998. Process of contamination by aflatoxin-producing fungi and their impact on crops. Pages 279-306 in: Mycotoxins in Agriculture and Food Safety. K. K. Sinha and D. Bhatnagar, eds. Marcel Dekker, New York.

38. Preuss, D., Lemieux, B., Yen, G., and Davis, R. W. 1993. A conditional sterile mutation eliminates surface components from Arabidopsis pollen and disrupts cell signaling during fertilization. Genes Dev. 7:974-985.

39. Scott, G. E., and Zummo, N. 1988. Sources of resistance in maize to kernel infection by Aspergillus flavus in the field. Crop Sci. 28:504-507.

40. Steiner-Lange, S., Fischer, A., Boettcher, A., Rouhara, I., Liedgens, H., Schmelzer, E., and Knogge, W. 2003. Differential defense reactions in leaf tissues of barley in response to infection by Rhynchosporium secalis and to treatment with a fungal avirulence gene product. Mol. PlantMicrobe Interact. 16:893-902.

41. Takahashi, R., Joshee, N., and Kitagawa, Y. 1994. Induction of chilling resistance by water stress, and cDNA sequence analysis and expression of water stress-regulated genes in rice. Plant Mol. Biol. 26:339-352.

42. Thomann, E. B., Sollinger, J., White, C., and Rivin, C. J. 1992. Accumulation of group 3 late embryogenesis abundant proteins in Zea mays embryos. Plant Physiol. 99:607-614.

43. van Loon, L. C., Pierpoint, W. S., Boller, T., and Conejero, V. 1994. Recommendations for naming plant pathogenesis-related proteins. Plant Mol. Biol. Rep. 12:245-264.

44. van Loon, L. C., and van Strien, E. A. 1999. The families of pathogenesisrelated proteins, their activities, and comparative analysis of PR-1 type proteins. Physiol. Mol. Plant Pathol. 55:85-97.

45. Warner, S. A. J., Scott, R., and Draper, J. 1992. Characterization of a wound-induced transcript from the monocot asparagus that shares similarity with a class of intracellular pathogenesis-related (PR) proteins. Plant Mol. Biol. 19:555-561.

46. Widstrom, N. W., McMillian, W. W., and Wilson, D. M. 1987. Segregation for resistance to aflatoxin contamination among seeds on an ear of hybrid maize. Crop Sci. 27:961-963.

47. Woloshuk, C. P., Cavaletto, J. R., and Cleveland, T. E. 1997. Inducers of aflatoxin biosynthesis from colonized maize kernels are generated by an amylase activity from Aspergillus flavus. Phytopathology 87:164-169.

48. Xu, D., Duan, X., Wang, B., Hong, B., Ho, T. H. D., and Wu, R. 1996. Expression of a late embryogenesis abundant protein gene, HVA1, from barley confers tolerance to water deficit and salt stress in transgenic rice. Plant Physiol. 110:249-257. 